$$
\begin{aligned}
& \text { AEO WISEO } \\
& \text { AUG Og } 103 \\
& \text { OSTI }
\end{aligned}
$$

\title{
Thermal Stresses in the Microchannel Heatsink Cooled by Liquid Nitrogen
}

\author{
Robert A. Riddle
}

This paper was prepared for presentation at the SPIE's International Symposium on Optics, Imaging, and Instrumentation Session: High Heat Flux Engineering II July 11-16, 1993

San Diego, California

June 30, 1993

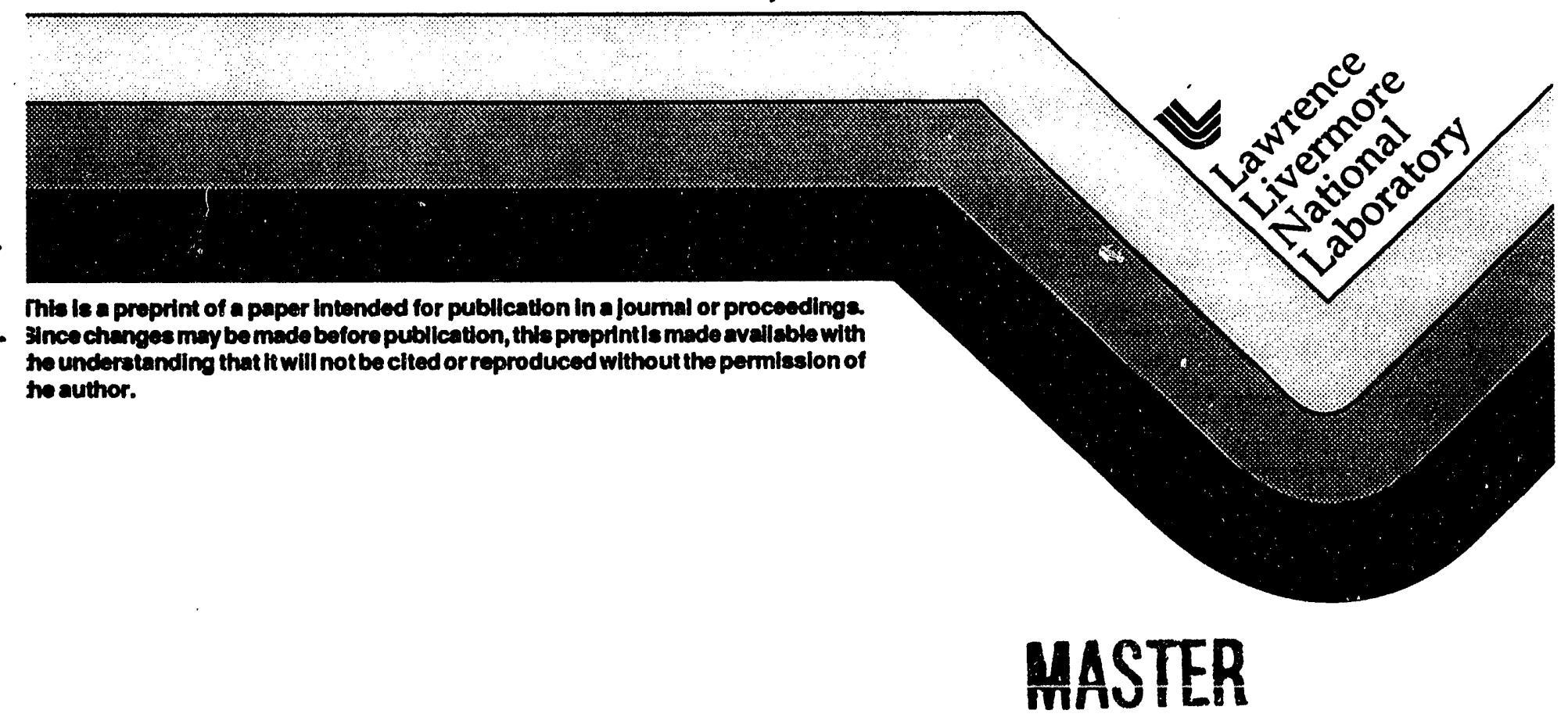




\section{DISCI.AIME.R}

This decument was prepared as an account of work sponsored by an akency of the United Stales Government. Neither the Uniled States Government nor the University of California nor any of their employees, makes any warranty. express or implied, or assumes any legul liability or respunsibility for the accuracy. completeness, or usefulness of any information, apparatus, product, or process disclosed, or represents that its use would not infringe privately owned rights. Reference herein to any specific cummercial products. process, or service by trade name, trademark, manufacturer, or otherwise, deces not necessurily constitufe or imply its endorsement, recommendation. or favoring by the United Siates Government or the linicersity of California. The views and opinions of authors expressed herein do not necessarily state or reflect those of the Inited States Government or the University of Culifornia, and shall not be used for advertising or product endorsement purposes. 


\title{
Thermal Stresses in the Microchannel Heatsink Cooled by Liquid Nitrogen
}

\author{
Robert A. Riddle \\ Lawrence Livermore National Laboratory \\ Livermore, California
}

\begin{abstract}
Microchannel heatsinks represent a highly efficient and compact method for heat removal in high heat flux components. Excellent thermal performance of a silicon microchannel heatsink has been demonstrated using liquid nitrogen as the coolant. For the heating of a 1 square centimeter area, at a heat dissipation of $500 \mathrm{~W}$, a typical silicon heatsink cooled by liquid nitrogen has a thermal resistance of $0.046 \mathrm{~cm}^{2 \circ} \mathrm{K} / \mathrm{W}$. The actual heatsink structure in this case is only $0.1 \mathrm{~cm}$ high.

Silicon, although it has excellent thermal properties at liquid nitrogen temperatures, may fracture with very little plastic deformation due to mechanical and thermal stresses. Because the fracture strength of silicon depends on the presence of small defects, strength of the heatsink structures must be addressed to insure highly reliable heatsink devices.

Microchannel heatsink reliability can be affected by thermal stresses that arise due to temperature gradients between the base and fin and along the fin length. These stresses are combined with the bonding stresses that arise in attaching components at elevated temperatures to the silicon heatsink and then cooling the structure to the cryogenic operating temperatures. These bonding stresses are potentially large because of the differences in the values of the coefficients of thermal expansion in silicon heatsink material, and the attached component materials.

The stress results shown for a 17:1 aspect ratio heatsink cooled in liquid nitrogen. The temperature gradients are a result of a surface heat flux of $1.3 \mathrm{~kW} / \mathrm{cm}^{2}$, approximating the heat dissipation of an RF power chip. The chip is connected to an aluminum nitride substrate, then the chip and substrate module are attached to the heatsink at a bonding temperature of $600^{\circ} \mathrm{K}$, as for a gold-tin eutectic bond. The stresses are shown to be within the allowables of the materials involved.
\end{abstract}

\subsection{Introduction}

The microchannel heatsink (MCHS) has beer shown to be a very effective structure in minimizing thermal resistance using liquid nitrogen as the coolant 1 . Using liquid nitrogen as the coolant in silicon microchannel heatsinks takes advantage the order-ofmagnitude increase in the thermal conductivity of silicon at this temperature. A large number of electronic devices possess enhanced operational efficiencies at cryogenic temperatures due to less circuit resistance and signal noise ${ }^{2}$. 
As an example of this microchannel heatsink performance, a 16.2 to 1 aspect ratio structure in silicon was cooled by liquid nitrogen. In this heatsink, the fin and channel widths were equal at $50 \mu \mathrm{m}$ each, and with a fin height of $810 \mu \mathrm{m}$. The aspect ratio used to characterize the heatsink geometry is the ratio of the fin height to width. The geometry of the microchannel heatsink with the flow manifold is seen in figures 1 and 2 . The channels were sawn into a $0.1 \mathrm{~cm}$ thick wafer. 229 channels were sawn for a flow width of $2.3 \mathrm{~cm}$ and with a flow length of $1.73 \mathrm{~cm}$. The heated area was $1 \mathrm{~cm}$ by $1 \mathrm{~cm}$ in dimension.

The area of the heated pad was controlled by the sputtering of a $2.3 \mu \mathrm{m}$ thick tungsten silicide layer onto the base of the silicon fin structure. A $1.5 \mu \mathrm{m}$ thick layer of silicon oxide is used to electrically isolate the silicon from the tungsten silicide. A glass manifold, as shown in figure 2 , is reflow bonded to the end of the fins and silicon boundary to complete the coolant channel geometry.

At a liquid nitrogen flow rate of $0.67 \mathrm{l} / \mathrm{min}$, and at a power level of $500 \mathrm{~W}$, the heatsink had a measured surface temperature rise of $23^{\circ} \mathrm{K}$. By dividing the surface temperature rise by the heat dissipated this defines the thermal resistance of the heatsink as $0.046 \mathrm{~cm}^{2 \circ} \mathrm{K} / \mathrm{W}$. Figure 3 shows a plot of the measured thermal resistance of a $16: 1$ heatsink as described. At lower power levels the thermal resistance is seen to rise slightly. In the power dissipation range of 200 to $400 \mathrm{~W}$, an average thermal resistance for this heatsink structure is $0.064 \mathrm{~cm}^{2}{ }^{\circ} \mathrm{K} / \mathrm{W}^{1}$.

Using the measured thermal performance of the heatsink as a guide, the heat transfer boundary conditions for the thermal stress analysis of the microchannel device can be derived to predict the temperatures and stress experienced by actual devices mounted on the heatsink surface.

\subsection{Thermal Gradients in the Fin}

For a 17:1 aspect ratio heatsink cooled by liquid nitrogen, conservatively using the larger low power ( single phase flow ) thermal resistance of $0.046 \mathrm{~cm}^{2 \circ} \mathrm{K} / \mathrm{W}$, a fin to coolant heat transfer coefficient of $10500 \mathrm{~W} / \mathrm{m}^{2}{ }^{\circ} \mathrm{K}$ is derived. The derivation of this average heat transfer coefficient is based on a correlation of the Nusselt number with the heatsink geometry 3 .

For an optimized silicon heatsink geometry cooled by liquid nitrogen, a much larger aspect ratio is required, on the order of 55:1. For an optimized heatsink of this geometry the assumption of an average, uniform heat transfer coefficient is much less acceptable 4 . However, for this case, where the aspect ratio is much less than the optimum, and the temperature gradients in the fin have been estimated by finite element analysis, the assumption of a constant heat transfer coefficient down the fin is reasonable.

For this 17:1 aspect ratio heatsink, with the heat transfer coefficient applied as described above, the temperature gradient down the fin was calculated to be $5^{\circ} \mathrm{K}$ over the 
$850 \mu \mathrm{m}$ length using the thermal finite element code TOPAZ2D 5 . Figure 4 shows a contour plot of temperature resulting from the analysis. The $32{ }^{\circ} \mathrm{K}$ maximum surface temperature rise above the coolant temperature at a power level of $500 \mathrm{~W} / \mathrm{cm}^{2}$ from this analysis corresponds well to the experimentally measured thermal resistances in this type of heatsink.

On the basis of on this confirmatory analysis, with the correlation with the experimental results and the small temperature gradients in the fin, using the average heat transfer coefficient over the entire fin surface of $10500 \mathrm{~W} / \mathrm{m}^{2 \circ} \mathrm{K}$ is adequately accurate.

\subsection{ThermaL_Analysis of the Microchannel_Heatsink}

Figure 5 shows the mesh of a silicon chip and substrate mounted on a microchannel heatsink. The $127 \mu \mathrm{m}$ thick by $3430 \mu \mathrm{m}$ wide chip is mounted using a thin film of gold, $38 \mu \mathrm{m}$ thick, to an aluminum nitride substrate. The gold layer represents both the bonding layer and the circuit ground plane. The $500 \mu \mathrm{m}$ thick substrate is borided through a $2.0 \mu \mathrm{m}$ thick gold layer to the top of the heatsink. The heatsink consists of a $150 \mu \mathrm{m}$ thick base region with $50 \mu \mathrm{m}$ fins and channels extending a distance of $850 \mu \mathrm{m}$. The heatsink and substrate are assumed to extend a considerable distance in the lateral direction, with many chips mounted on the substrate cooled by a single heatsink. The right hand portion of this figure shows the element size while the left hand portion shows the material boundaries. In the analysis only the right hand side is modeled, as it is the smallest symmetric unit of the overall geometry. The glass coolant manifold is not modeled as it makes little contribution to the thermal analysis.

In accordance with the symmetry condition the left and right hand sides in the thermal analysis are adiabatic boundaries. The heat flux which represents the dissipated power of the chip is $1.3 * 10^{7} \mathrm{~W} / \mathrm{m}^{2}$ or $45 \mathrm{~W}$ per chip and is assumed to occur at the chip top surface. All the heat is assumed removed at the fin boundaries with a convective heat transfer cisefficient of $10500 \mathrm{~W} / \mathrm{m}^{2}{ }^{\circ} \mathrm{K}$ into liquid nitrogen at $80^{\circ} \mathrm{K}$. The thermophysical material jroperties, heat capacity and thermal conductivity, are taken from a wide range of reference:s, and are given as a function of temperature where possible.

Figure 6 shows the contours of temperature from the finite element model of the heatsink and chip. This depicts the thermal gradients the chip produces as it operates continuously with liquid nitrogen cooling. The $110^{\circ} \mathrm{K}$ maximum chip temperature is near the upper range of its desired operating range.

\subsection{Operational Thermal Stresses}

The thermal field as shown in figure 6 is the input for the subsequent thermal stress finite element analysis using the code NIKE2D 6 . Of necessity the finite element meshes are identical. The material properties input include elastic modulus, poisson's ratio and 
coefficient of thermal expansion for all components. Elastic-plastic or strength properties for the gold are provided as yield stress and hardening modulus, where the silicon and aluminum nitride are strictly elastic.

The left hand side of the model is given the symmetry boundary condition of no displacement in the lateral or y direction. To model the constraint of the glass manifold the displacements in the vertical or $z$ direction at the bottom of the heatsink are set to zero. For comparison, the case where this constraint is removed was also calculated.

Figure 7 displays the contours of maximum shear stress in all the materials for these loading conditions. The maximum stress of $25.4 \mathrm{MPa}$ is found in the gold bond layer and circuit ground plane material just under the center ( left boundary in figure ) of the chip. This stress level is near the assumed yield level of the gold. The maximum effective stress in the silicon chip material adjacent to the high stress region is $4.34 \mathrm{MPa}$, while in the heatsink this stress component has a maximum value of $2.44 \mathrm{MPa}$.

Figure 8 shows the contours of stress, with the stress normal to the y or lateral direction. Here the maximum stress is in the aluminum nitride at the left boundary of the figure, near the aluminum nitride substrate to silicon heatsink boundary. The y stress here is at 11.0 MPa. The larger negative compressive stresses of $50.8 \mathrm{MPa}$ are in the center of the chip near the gold bond layer. The $\mathrm{z}$ or vertical direction stresses are typically a factor of ten less, with their maximum occurring near the chip edge.

The corresponding stress levels when the bottom layer of the heatsink is assumed free to move without constraint of the glass manifold are a few percent higher. The effect of the constraint in this case is relatively unimportant in these stress components.

\subsection{Thermal Stresses Due to Bonding}

For calculation of the thermal stresses due to the bonding fabrication step, two temperature states are considered. The first is a uniform temperature in all the materials of $600^{\circ} \mathrm{K}$, the temperature of the substrate to heatsink bond. The second state is a uniform temperature of $77^{\circ} \mathrm{K}$, the lowest temperature for the components at the start of an operational sequence using liquid nitrogen as the coolant This temperature difference with the different coefficients of thermal expansion of the materials is the cause of the thermal stresses due to bonding.

Figure 9 shows the contours of maximum shear stress for this case. Here the maximum stresses are in the aluminum nitride near the edge of the gold ground circuit material on the right hand side of the figure at a level of $33.6 \mathrm{MPa}$. The adjacent AIN substrate material is stressed to a level of $15.3 \mathrm{MPa}$ in a small region, with stress levels lessening rapidly as they spread out from this point.

Figure 10 depicts the contours of $y$ stress for the bonding thermal stresses. Here the maximum stresses are in the aluminum nitride near the edge of the gold ground circuit material on the right hand side of the figure at a level of $86.5 \mathrm{MPa}$. In the adjacent AIN 
substrate material the stress level is $11.2 \mathrm{MPa}$, while close by in the heatsink the maximum y stress level is $10.8 \mathrm{MPa}$. The locations of the maximum y stresses from the bonding process are different and relatively far removed from the location of the maximum y stress for the operational thermal stresses.

\subsection{Combination of the Thermal and Mechanical Stresses and Application of a Failure Theory}

Because there is little or no plastic deformation in these stress analyses, they may be elastically superpositioned to consider the combined effect of the operational and bonding thermal stresses. Likewise, the stresses due to internal pressure of the coolant could be superposed, as could the stresses on the heatsink and substrate module due to the clamping forces to hold the module to the inlet and outlet cooling ports. These latter stresses are small under the design conditions ( the heatsink is manufactured and attached correctly ).

The stresses due to the operational thermal gradients and the bonding cooldown may be simply added in the cases of the direction normal stresses presented because of the superposition principle. The maximum shear stresses must be combined with more care because they represent a difference in the principal normal stresses.

In studying the stresses and deflections due to the bonding and operational thermal stresses it becomes apparent that in general the stress fields tend to cancel each other out. That is, where the y stresses due to the operational thermal gradients are large and positive in the aluminum nitride layer, the y stresses due to the bonding process are small and negative. Combining these two stress states lowers the resulting stresses everywhere it has been examined.

One of the most difficult challenges of the stress analysis is to describe the allowable stress levels which represent failure limit. Because silicon is a brittle material that fractures, and is hence very sensitive to minute flaws, on the order of 10 nanometers in size $^{7}$, the question of the appropriate stress level implies a knowledge of the distribution of flaws in the structure. But because the flaws are typically beyond the limit of resolution of non-destructive examination techniques, one must assume an approximate uniform distribution of typical flaws, and measure the load to failure under loading conditions comparable to those in question.

Here two experimental ubservations are useful in approximating a stress allowable. Flexure tests on notched specimens taken from similar silicon wafers showed an average stress allowable of $140 \mathrm{MPa}^{8}$. Also, in performing tests to qualify a bond method for connecting the aluminum nitride substrate to a silicon heatsink it was found that at a bonding temperature of $1100^{\circ} \mathrm{K}$ failure could occur in the heatsink. A strength of materials calculation for this situation resulted in a silicon stress failure level of $90 \mathrm{MPa}$.

In these analyses, the stresses in the silicon are much less than this allowable. The stress allowable for the aluminum nitride is taken to be $290 \mathrm{MPa}$. The failure of the gold is defined by a deformation limit not reached in this type of bonding conditions. 


\subsection{Conclusions}

The temperature fields present in microchannel heatsinks using single phase fluids as the cooling media are beginning to be well understood. There is a wide range of analytical tools and experimental data to support this conclusion. The very important work to understand thoroughly the thermal and mechanical stresses in microchannel heatsinks due to the operating thermal gradients and manufacturing cooldown has begun. The aim of this work is to increase the reliability of microchannel heatsinks and insure a their widespread use in high heat flux applications.

\subsection{References}

1. Riddle, R.A., and Bernhardt, A.F.,"The Microchannel Heatsink with Liquid Nitrogen Cooling," in High Heat Flux Engineering, Ali M. Khounsary, Editor, Proc. SPIE 1739,pp. 51-59 (1993).

2. Kirschmnan,R.K.,1990,"Low-Temperature Electronics",IEEE Circuits and Devices Magazine,March 1990,pp.12-24.

3.Shah,R.K., and London,A.L., "Laminar Flow Forced Convection in Ducts",Supplement 1, in Advances in Heat Transfer,Eds. Irvine, T.F. and Hartnett,J.P.,Academic, New York,1978.

4. Landram,C.S.,"Computational Model for Optimizing Longitudinal Fin Heat Transfer in Laminar Internal Flows," Lawrence Livermore National Laboratory UCRL-JC105437, November, 1990.

5. Shapiro, A. B.,"TOPAZ2D-- A Two-Dimensional Finite Element Code for Heat Transfer Analysis, Electrostatic, and Magnetostatic Problems", Lawrence Livermore National Laboratory UCID-20824,July 1986.

6. Engelmann, B., and Hallquist, J.O.,"NIKE2D-- A Nonlinear, Implicit, TwoDimensional Finite Element Code for Solid Mechanics,"Lawrence Livermore National Laboratory UCRL-MA-105413,April 1991.

7. McLaughlin, J.C. and Willoughby, A.F.W.,"Fracture of Silicon Wafers,"Journal of Crystal Growth,85 (1987),pp.83-90.

8. Freeman,D.,"Effects of Saw Cuts on Silicon Hybrid Wafer Scale Computer Components",Lawrence Livermore National Laboratory,private communication, August 1990.

9. Miyashiro,F. et al.,"High Thermal Conductivity Aluminum Nitride Ceramic Substrates and Packages," IEEE Transactions on Components, Hybrids, and Manufacturing Technology, Vol. 13,No.2,June 1990,pp.313-319.

This work was performed under the auspices of the U.S. DOE by LLNL under contract no. W-7405-Eng-48. 


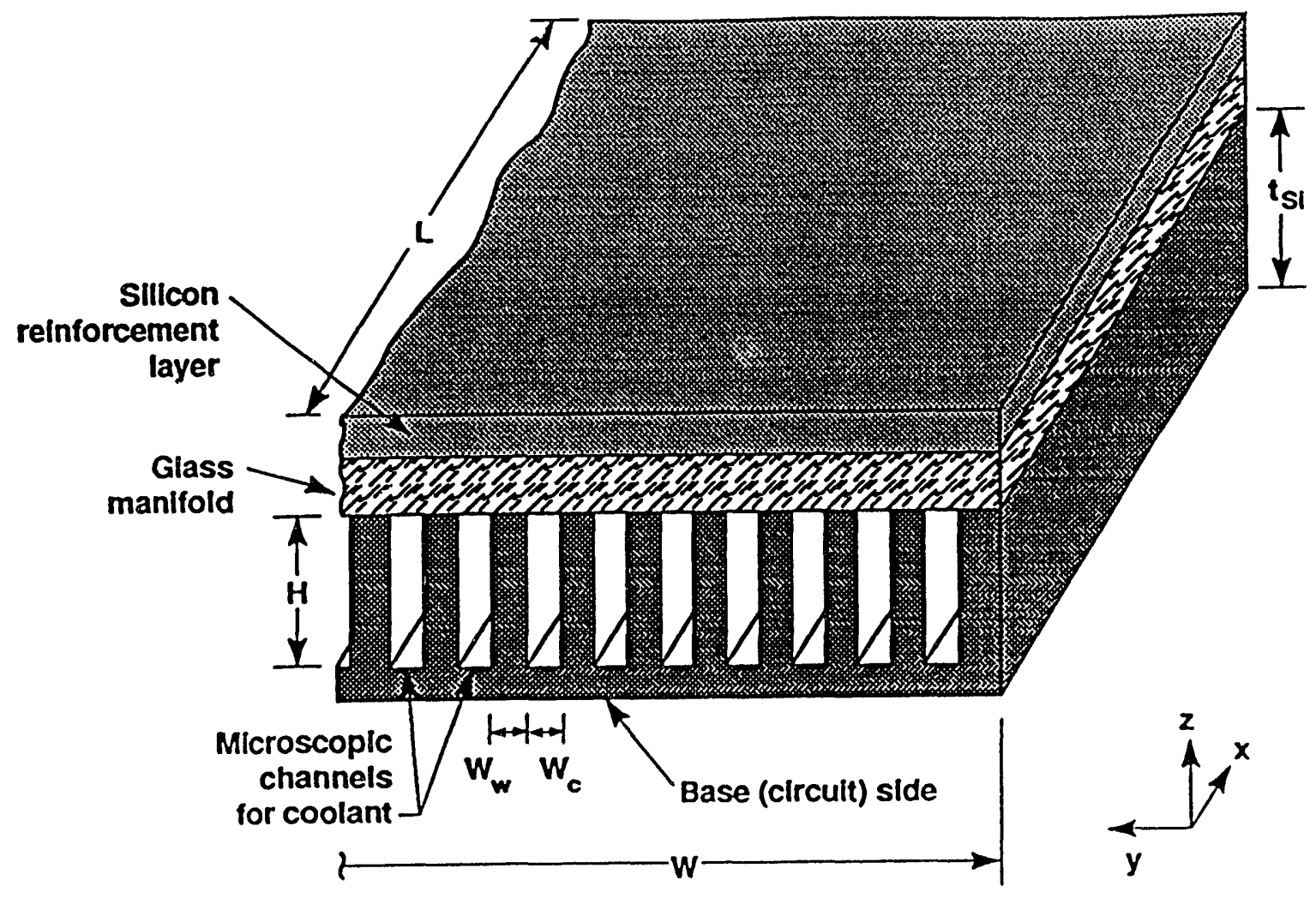

Figure 1
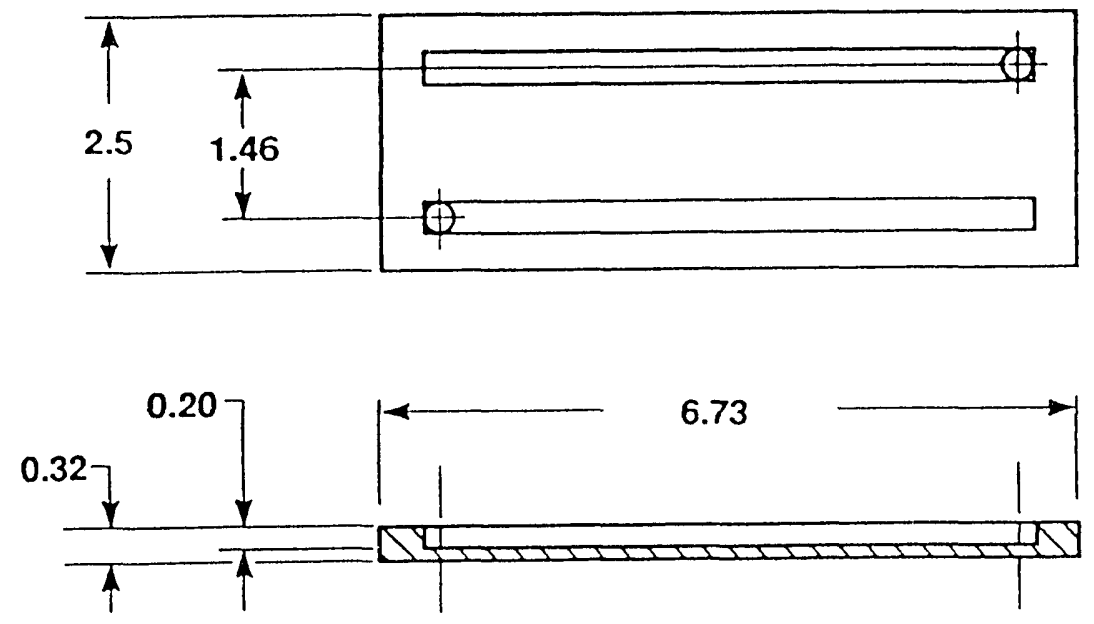

Figure 2 


\section{Data from a 16:1 Aspect Ratio Heatsink with Liquid Nitrogen Cooling}

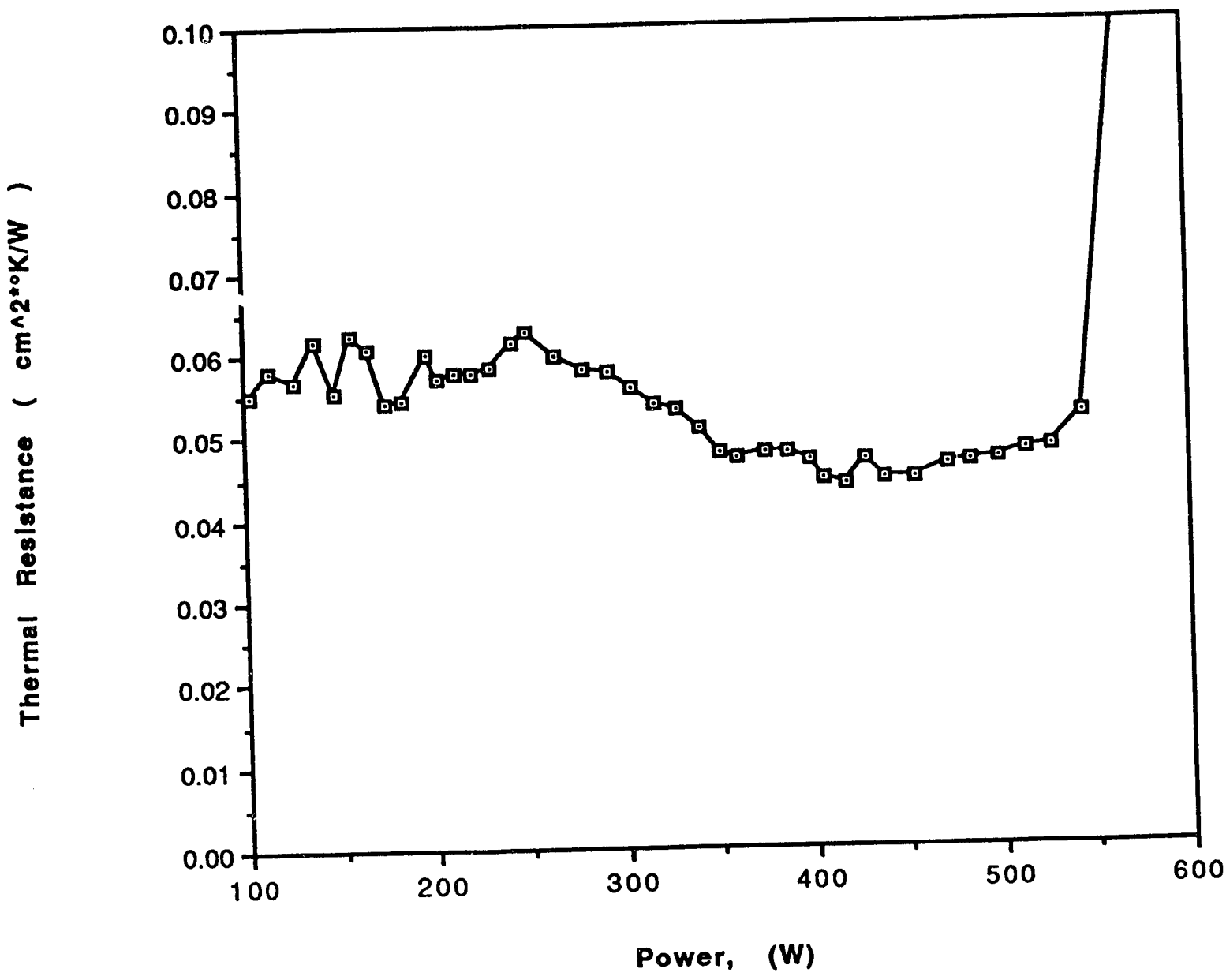

therm. res.

Figure 3 
N⿴囗十 $++0$

w)

nN 1

बन -

its

- 2

$1+8$

중

$\pm \frac{0}{6}$

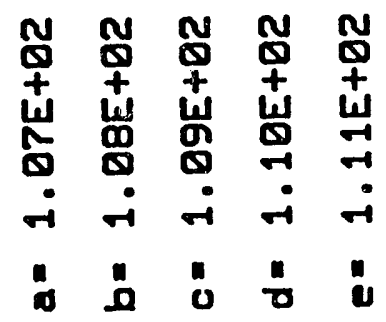

$60-380^{\circ}$

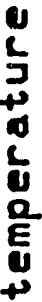

$60-380 \cdot 6$

$60-300^{\circ} 8$

$10-300 \cdot 2$

$48-3108^{\circ} 9$

$40-380^{\circ} \mathrm{s}$

$60-380^{\circ}$

Ui)

둥

$10-300^{\circ} \varepsilon$

a 0

임

$+t$

以岕

ํㅗㅇํำ

옹

$\alpha \boldsymbol{\Delta}$

峞

足

L

บ

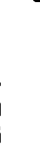
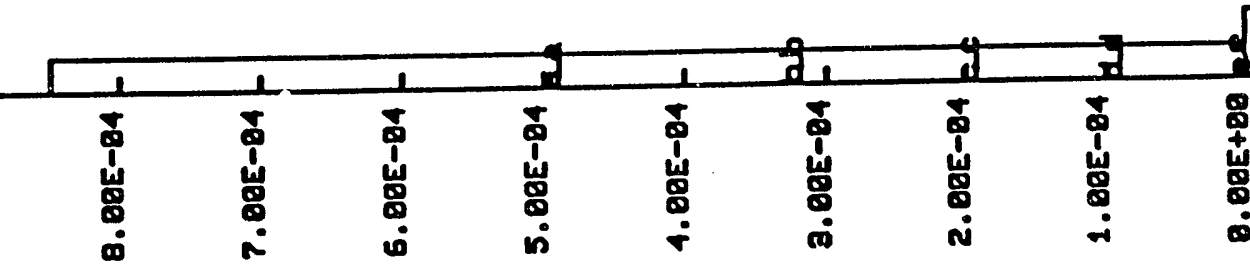

$28-300 \cdot T$ 


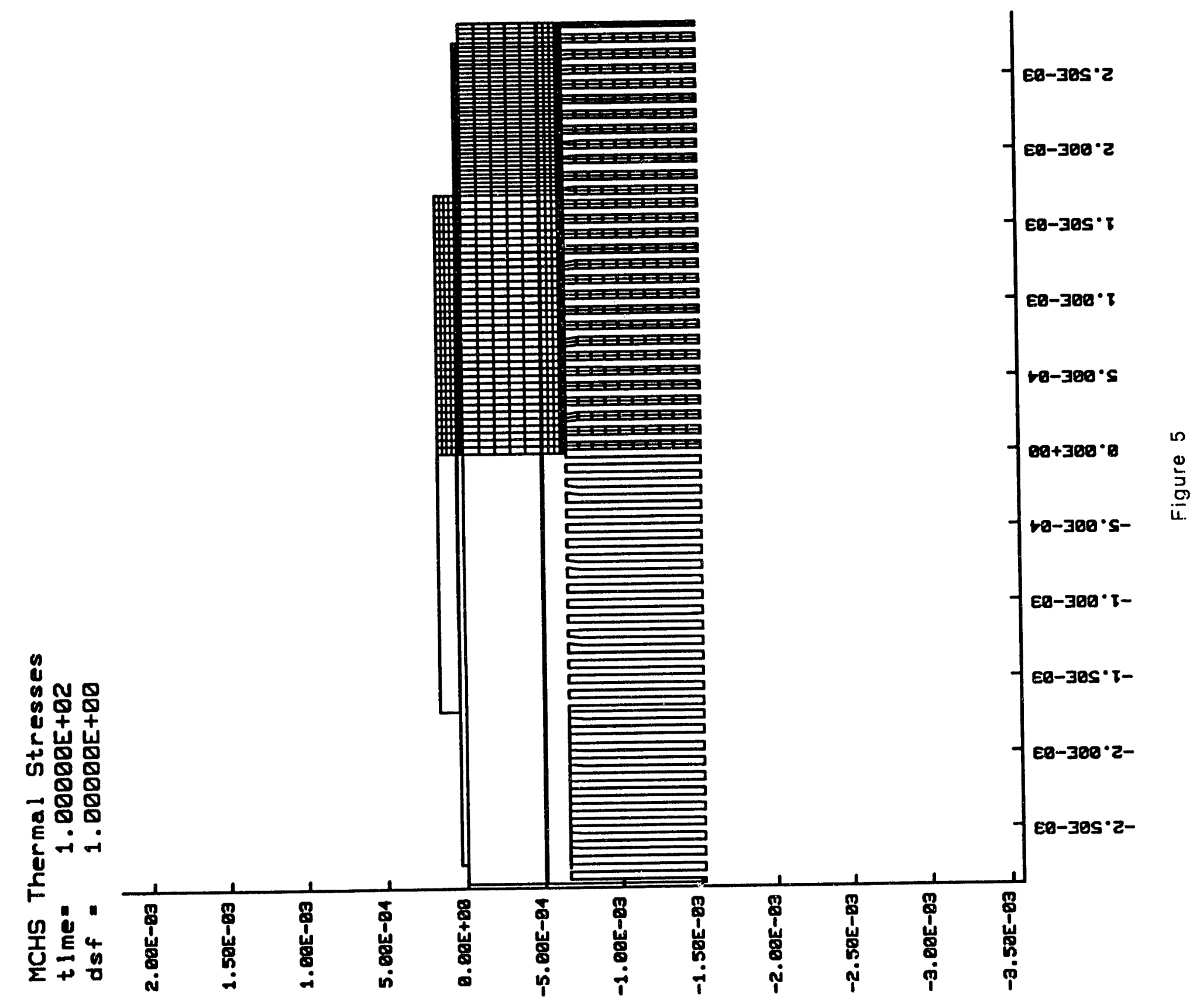




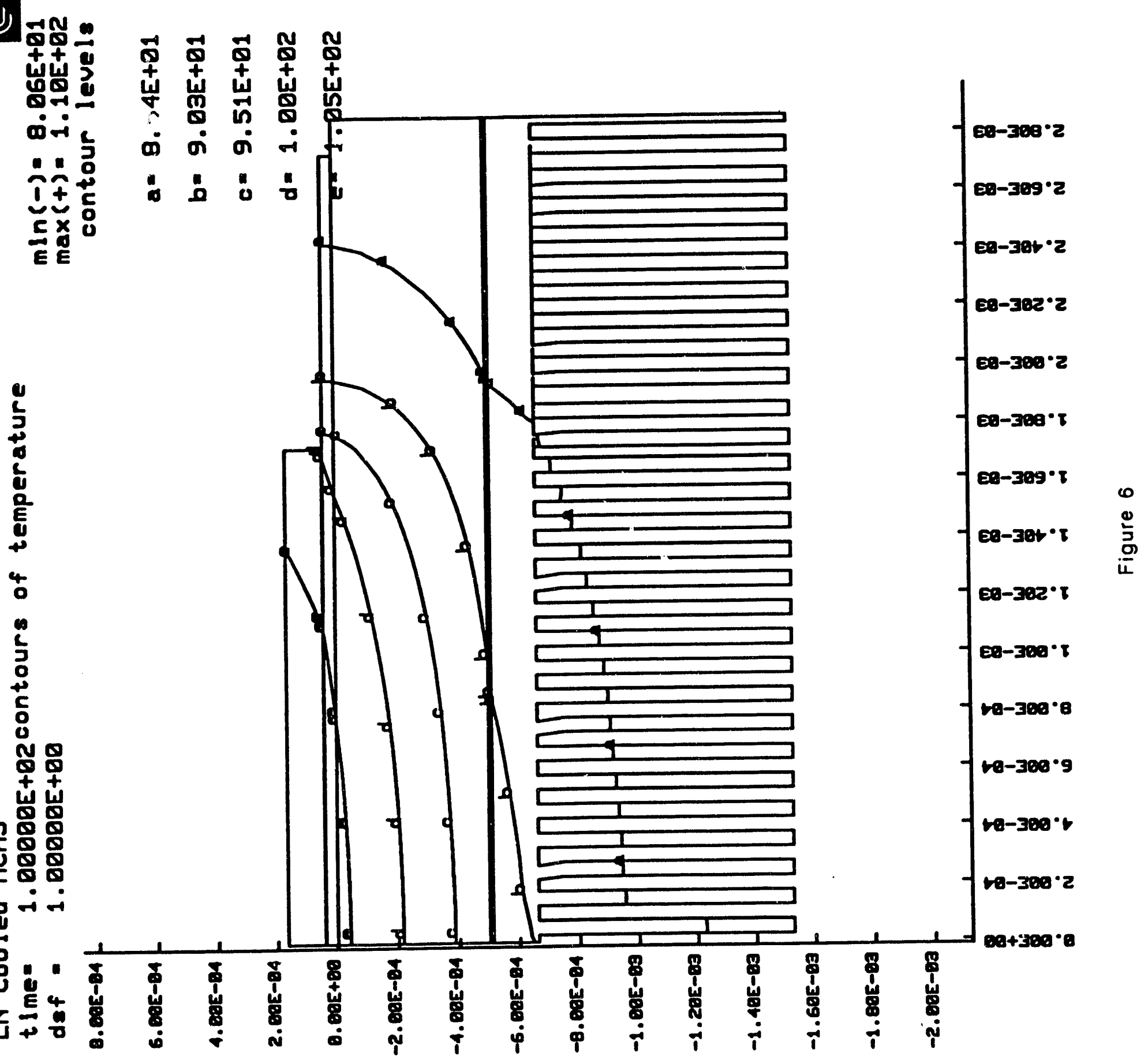




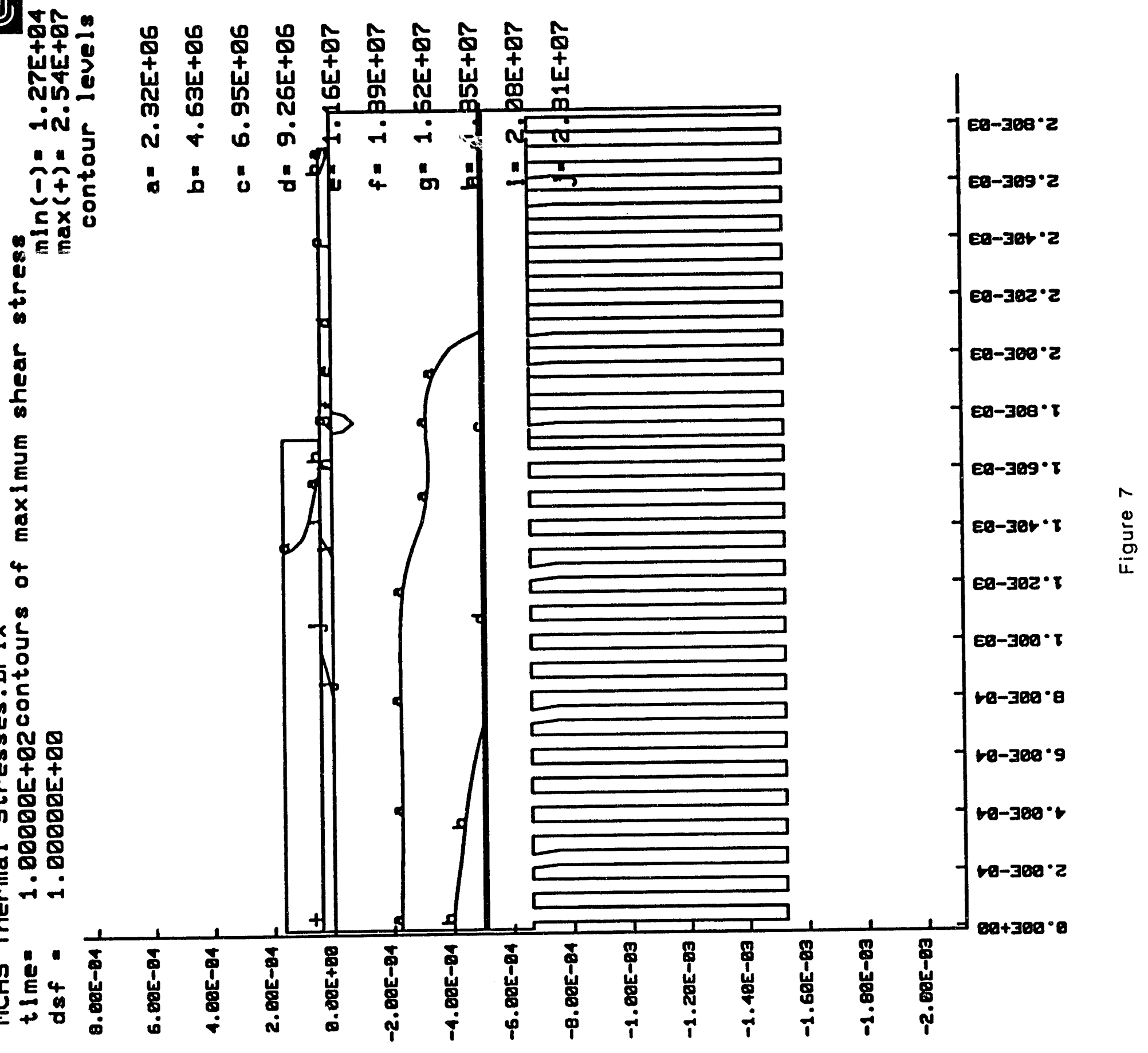




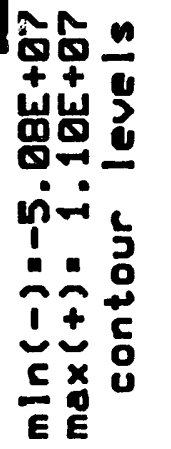
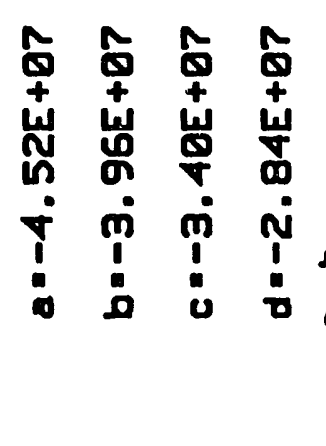

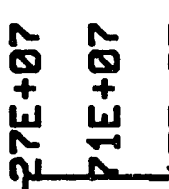

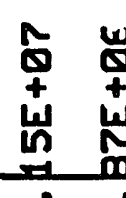

岗员 志志<smiles>C1[C]2C[C]12</smiles>

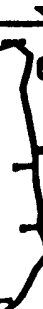

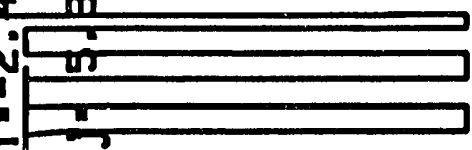

$68-300^{\circ} 2$

$60-369 \cdot 2$

E0-30r'2

$68-382 \cdot 2$

$60-380 \cdot 2$

$68-388^{\circ} 1$

$\frac{1}{4}$

ग

4

$+2$

$\times 5$

备

C

$\because \frac{1}{0}$

00

* N N

00

C U U

+ 10

ก 0

ธิ

- $\mathbf{0}$

๑ 0

E -

E

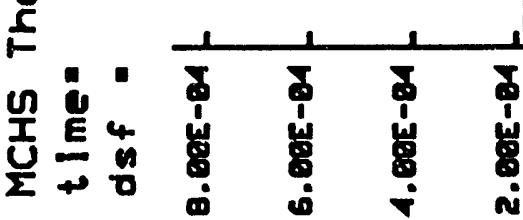

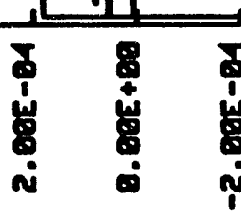

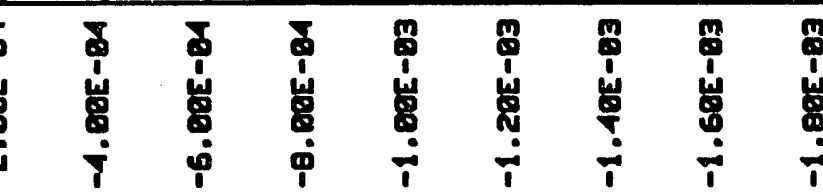

$\stackrel{\infty}{\stackrel{0}{\supset}}$

$68-302 \cdot 1$

$60-380^{\circ} I$

$10-380 \cdot 8$

$10-308 \cdot 9$

$10-380^{\circ}$

$10-380 \cdot 2$ 


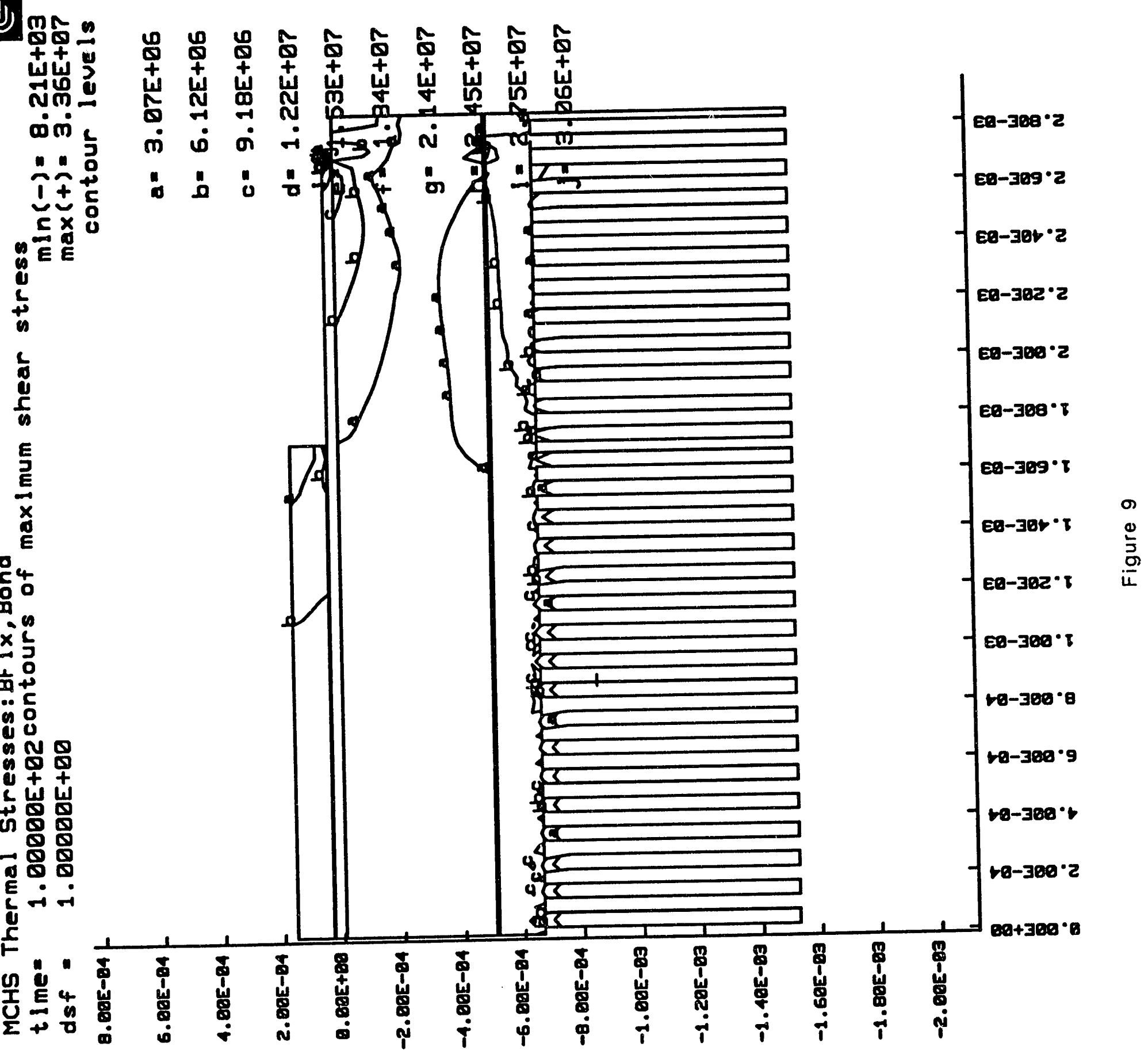




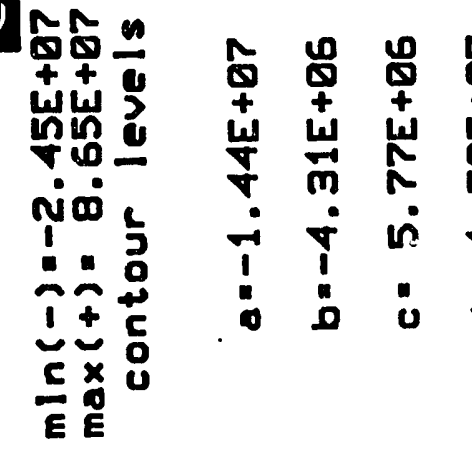

$n$
0
0
0
0

कृ

$\times \frac{1}{2}$

$\ln$

$\because$ C

\&u

N N

00

c un

ث心

ย 0

Q

$0 \otimes$

E $:$ i

E

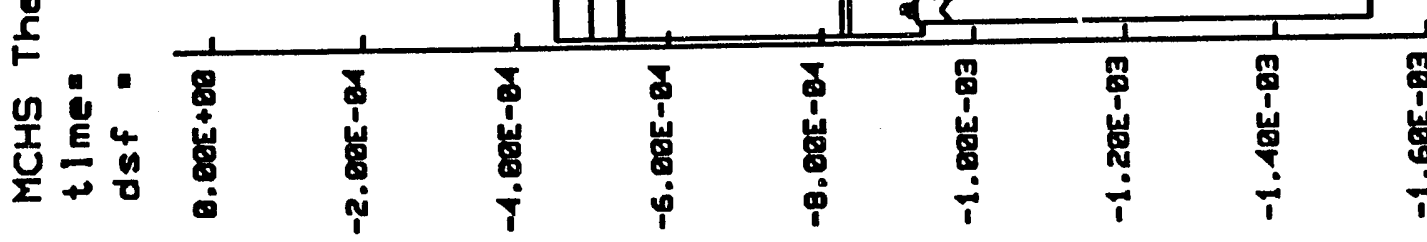

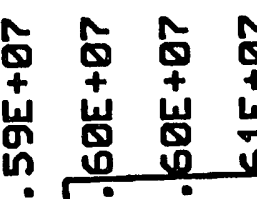

尺.

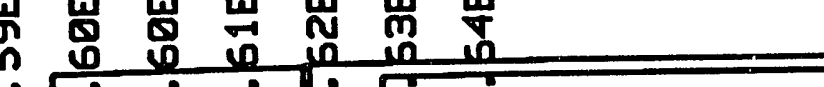

政

$\dot{1}$ क

कy

$60-36 \theta^{\circ} 1$

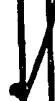

\{

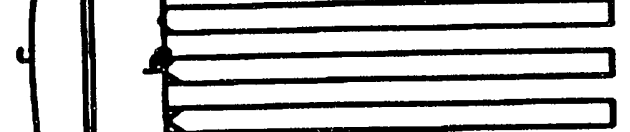

e8-389.

88-39r'

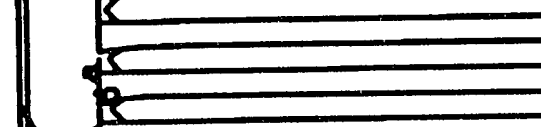

$E 0-302 \cdot 1$

E9-380.

음
은
몬

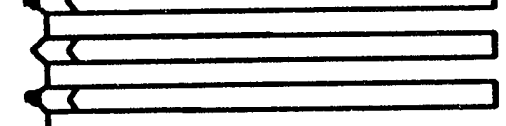

1

a-300.

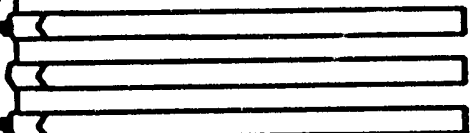

$10-300$

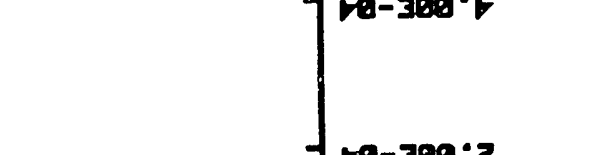



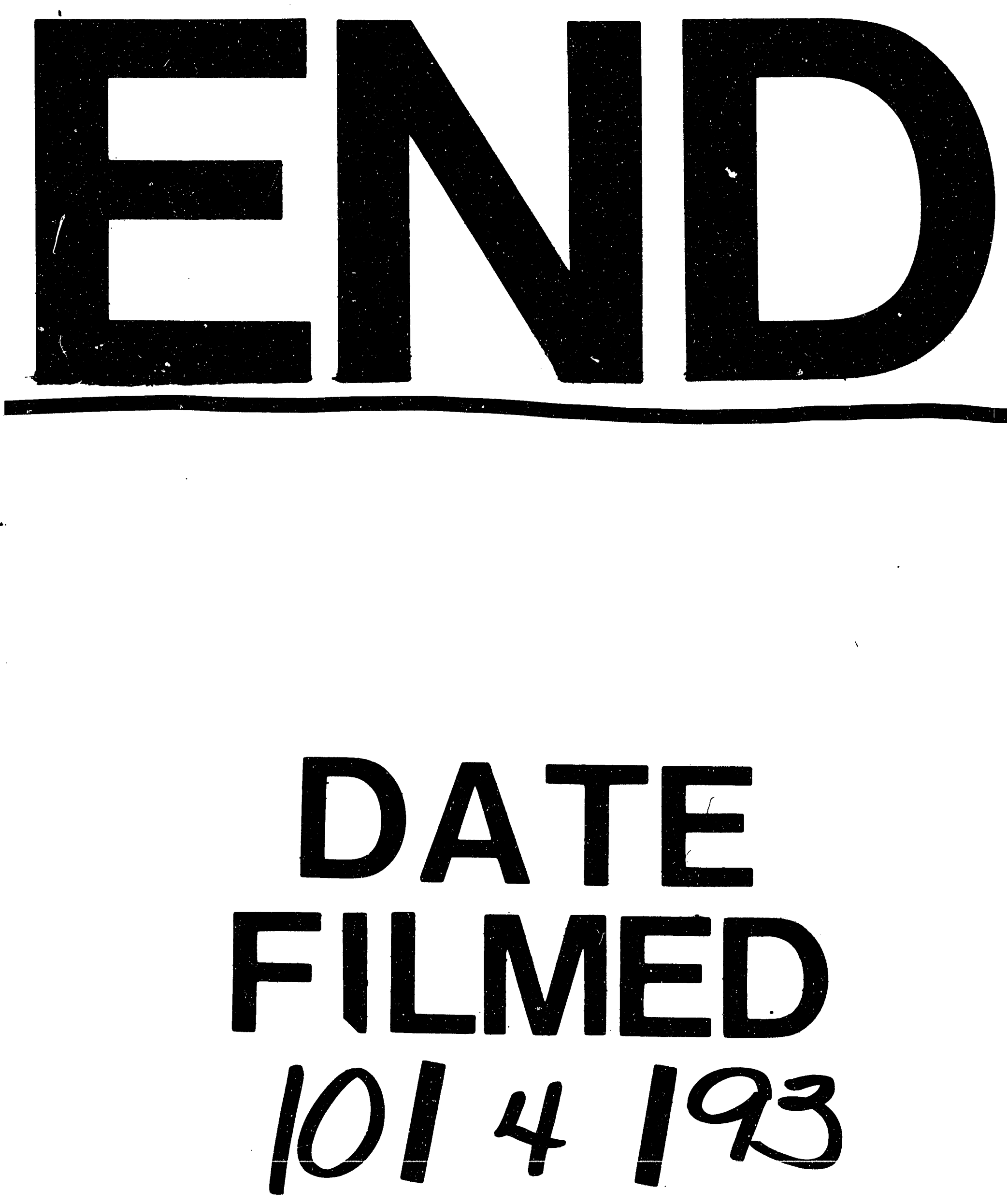
